\title{
Bone Fracture Modeling and Analysis by Three Point Bending: A Review
}

\author{
Mohammad Shahril Salim, Ahmad Faizal Salleh and Ruslizam Daud \\ School of Mechatronic Engineering, Universiti Malaysia Perlis (UniMAP), 02600 Arau, Perlis, Malaysia
}

\begin{abstract}
Bones are the main structural components of a skeleton in our body. They run as a special role in the body providing its shape maintenance, protection of internal organs and transmission of forces. Their structural integrity is essential for the quality of life. Unfortunately, bones can only sustains loads until it reach a certain limit. Understanding fracture behaviour of bone is necessary for prevention and diagnosis of trauma. This paper aims to review and update readers on current published research explicitly related to bone fracture analysis conducted by three point bending test. Past studies have shown that most analysis have been done on fracture mechanism and how to find fracture toughness of the bone. Besides using an experimental approached, some of the research used Finite Element (FE) as a tool to investigate the fracture mechanism.
\end{abstract}

\section{Introduction}

When participating in any collision sports, there will be a risk of injury as the dynamic impact of the collision may overload the musculoskeletal system beyond its limit. The general risk factors for injuries have been addressed to be skill, Body Mass Index (BMI), playing experience, equipment, previous injury, playing position, and level of play or competition. But, the most common related injuries are fractures. Fractures are very common scenario in our life. Basically it will occur when the physical force exerted on the bone is much stronger than the bone itself. As we getting older, our bones become more brittle and we are more likely to suffer fractures from falls that would not occur when we were young [1]. Bone fracture toughness and bone resistance to crack growth is a key factor in resistance of bone to monotonic and fatigue failure. There are two main important occur in fracture toughness which are intrinsic and extrinsic mechanism. Intrinsic mechanism is about the plasticity deformation at small scale lengths while extrinsic refer to crack shielding where microstructure inhibit the crack growth.

The mechanical properties of bone are determined by their composition and structure over length - scales, and influenced by the loads it supports through adaptation and remodelling. As we all knew, bone is a living tissue. Thus it might be always response to mechanical stimuli. Because of the response, the structure of bone is result from the continous stress induced modelling. At the macroscopic scale, bone is composed of cortical bone and trabecular bone. Encouraged by the idea that an accurate evaluation of bone quality could potentially be a predictor of risk of bone fracture, recent studies on the fracture properties of bone have focused on understanding the origin of bone toughness and its resistance to crack propagation in relation to bone's multi-scale structure [2], [3]. Despite the current understanding of the origins and mechanisms of toughening in human bone, it is still not fully understood how specific disease states can affect these mechanisms and how certain therapies can improve bone toughness to reduce the fracture risk. Mostly, an evaluation will be done by using animal models of human bone to predict the outcome of therapies in humans. An understanding of how fracture mechanisms change for different bone diseases and with different therapies is critical to the design of effective treatments on any diseases [4]. The fracture toughness of human cortical bone under mixed mode loading can be calculated using the Linear Elastic Fracture Mechanics (LEFM) assessment of critical stress intensity factor $\mathrm{K}_{\mathrm{IC}}$ in Mode I or $\mathrm{K}_{\mathrm{IIC}}$ in Mode II. However, instead of using the LEFM, the plastic behavior part which required the adoption of nonlinear fracture mechanics can be used by determining the value of $\mathrm{J}$ integral based on Strain Energy Released Rate (SERR).

Current practice to determine bone tissue modulus and fracture toughness is from three-point bending test. Despite the high clinical relevance of bone fractures, there is a lack of validated Finite Element (FE) models describing the complete fracture behavior. FE model can be used to represent an analysis under similar conditions as in the experiment. FE analysis is considered nowadays as a standard tool for the assessment of the mechanical properties of bone. It is acknowledged that, the finite element models used only provide a very simplified representation of a bone segment, however their simplicity lends clarity to the observation of different responses. Computational FE models present a method of studying complex mechanical interactions without 
introducing artificial foreign bodies and can provide a more continuous description of tissue behaviour. Although it provide a very simplified representation of any segment, however it simplicity lends clarity to observation of different impact responses when more or less representative organic tissue models are employed.

\section{Literature Review}

Bone is a great topic of interest for researchers. Understanding the structure-related properties of bone and how they are affected by aging, disease and therapies are very interesting area. Most of previous studies have used animal's bone compared to human bone. Little is known about the mechanisms of mouse bone fracture and its similarities and differences from fracture in human bone. Carrieo et al. investigated the fracture toughness during crack initiation and crack propagation for mouse bone. In the study, they monitored the extension of stable crack growth in mouse femora by simultaneously imaging the crack path during toughness measurement to discern the sources of toughness. Enviromental scanning electron microscope (ESEM) is used to measure the crack-initiation toughness and crack-resistance curve (Rcurve). This has been done to identify the salient damage and toughening mechanisms [4]. Bones were tested in three-point bending with a span of $6 \mathrm{~mm}$ (span/femur radius ratio of $\sim 4$ ) using Gatan Microtest $2 \mathrm{kN}$ three-point bending stage as in Fig. 1.

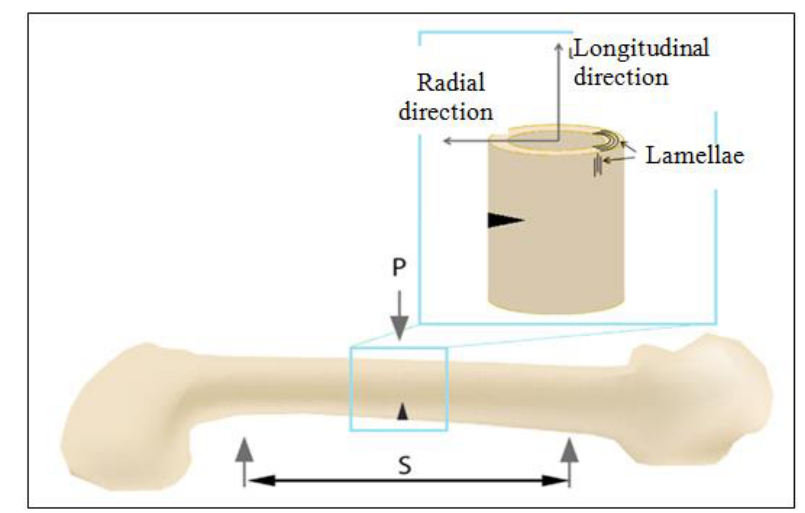

Figure 1. Fracture toughness testing performed on mouse femurs with a through-thickness sharp notch on the posterior side loaded in three-point bending in ESEM [4].

Fracture toughness values were then been evaluated by using the LEFM for a through-thickness crack in a circular thick-walled cylinder:

$$
K=F_{b} \frac{P S R_{o}}{\pi\left(R_{o}^{4}-R_{i}^{4}\right)} \sqrt{\pi R_{m} \theta_{i n s t}}
$$

where $F_{\mathrm{b}}$ is a geometric constant for thick-walled cylinders, $\mathrm{P}$ is the instantaneous load, $S$ is the span width, $R_{\mathrm{m}}, R_{\mathrm{i}}$, and $R_{\mathrm{o}}$ are the mean, inner and outer radius of bone and $\theta_{\text {inst }}$ is the instantaneous instability half-crack angle.

The majority of the works found in the literature regarding the fracture characterization of cortical bones are dedicated to mode I (opening) loading. S. Li et al. in their study considered a bovine femoral cortical bone tissue. The focused was on understanding of the principal and causes of bone fracture by considering the effect of both crack propagation direction and cortex position. The setup of the test is shown in Fig. 2.

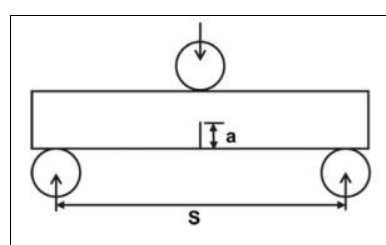

(a)

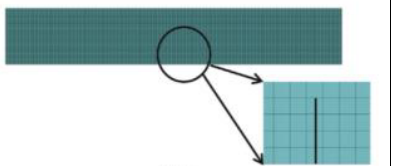

(b)

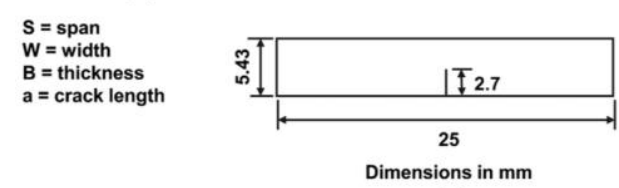

(c)
Figure 2. (a) Schematic of used three-point bending setup, distance between fixed grips is $\mathrm{S}=4 \mathrm{~W}$; (b) mesh used for cortical bone specimen; (c) geometry and dimensions of cortical bone specimens used [5].

In the study, the behaviour of all specimens was predominantly non-elastic [5]. Therefore, an elastic-plastic fracture mechanics (EPFM) parameter, J-integral was calculated based on British Standard BS 7448-1 [6]:

$$
J=\left[\frac{F S}{B W^{1.5}} \times f\left(\frac{a_{0}}{W}\right)\right]^{2} \frac{\left(1-v^{2}\right)}{E}+\frac{2 U_{p}}{B\left(W-a_{0}\right)}
$$

where $S$ is the bending span, $F$ is the applied force, $f\left(\mathrm{a}_{\mathrm{o}} / \mathrm{W}\right)$ is a function of $\left(\mathrm{a}_{\mathrm{o}} / \mathrm{W}\right), v$ is Poisson's ratio, $E$ is elastic modulus, $U_{\mathrm{p}}$ is the plastic part of area under plot of force versus specimen displacement along the load-line, $B$ is the specimen's thickness, $W$ is the effective width of the test specimen and $\mathrm{a}_{0}$ the average original crack length.

Fracture characterisation under mode II loading has been incomparably have less studied than mode I. This is probably because the fracture tests for this pure loading mode are very hard to perform in cortical bone. But, N. Dourado et al. have performed an end notch flexure test in the context of pure mode II fracture characterization of bovine cortical bone. To overcome the difficulties intrinsic to crack length monitoring during its propagation an identical crack method was employed as data reduction scheme. Fracture behaviour of each specimen was discovered by inverse method, considering a trapezoidal shape for the softening law. The consistency of obtained results leads to the conclusion that the trapezoidal law is sufficient to simulate fracture behaviour of bone under mode II loading and also very simple to be executed [7].

Besides using mode I and II, several researches have also been done on mixed-mode I+II loading. From a physiological point of view, fracture in bone is rarely induced by pure loading mode conditions. Therefore, crack initiation and propagation is more likely to occur under mixed-mode loading. Only a few works have been published so far regarding the mixed-mode loading. Silva et al. analysed a mixed-mode fracture characterization on 
human cortical bone from two tibiae of young male donors. Only the medial region (mid-shaft) of each tibia was used in the study. The main objective of their work is to verify the validity of using the Single Leg Bending (SLB) (Fig. 3) under mixed-mode I+II loading. The SLB is a simple three-point bending test on a pre-cracked specimen with a cut arm to induced mixed-mode I+II loading with nearly fixed ratio [8].

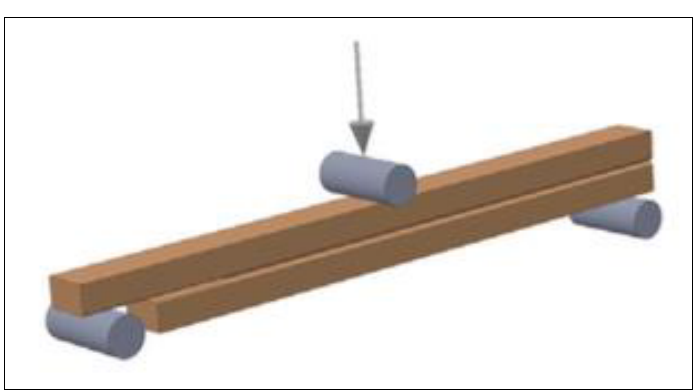

Figure 3. Single leg bending (SLB) [8]

It was verified that experimental values of fracture energy under mixed-mode I+II are very uniformly consistent with each other since a small coefficient of variation was obtained. The determination of the cohesive laws under mixed-mode can be viewed as a fundamental task in studies involving aspects that can affect bone fracture resistance.
T.L. Norman et al. have conducted a study using the compact tension method to determine the fracture toughness indices, critical energy release rate $\left(G_{\mathrm{c}}\right)$ and critical stress intensity factor $\left(K_{\mathrm{c}}\right)$ for human Haversioan bone and bovine bone under mode I loading. $K_{\mathrm{c}}$ and $G_{\mathrm{c}}$ are derived from theory based on LEFM. Results from this study show that the absolute values of $K_{\mathrm{c}}$ and $\mathrm{G}_{\mathrm{c}}$ for human bone are lower than the absolute values of $K_{\mathrm{c}}$ and $G_{\mathrm{c}}$ for bovine bone [9]. The test was conducted over a crack range of $0.5<a / W<1.0$ while previous studies as in Table I were conducted for $a / W<0.7$.

Table 1. Summary of previous study of fracture toughness of cortical bone using compact tension method

\begin{tabular}{|c|c|c|c|c|}
\hline $\begin{array}{c}\text { Investi- } \\
\text { gator(s) }\end{array}$ & $\begin{array}{c}\text { Bone } \\
\text { Type }\end{array}$ & $\begin{array}{c}\text { Orien- } \\
\text { tation }\end{array}$ & $\begin{array}{c}\mathbf{K}_{\mathbf{c}} \\
\mathbf{( \mathbf { M N }} \\
\mathbf{m}^{-\mathbf{3} / \mathbf{2}} \mathbf{)}\end{array}$ & $\begin{array}{c}\mathbf{G}_{\mathbf{c}} \\
\mathbf{( N m}^{-\mathbf{1}} \mathbf{)}\end{array}$ \\
\hline $\begin{array}{c}\text { Wright and } \\
\text { Hayes } \\
(1977)\end{array}$ & $\begin{array}{c}\text { Bovine } \\
\text { femur }\end{array}$ & $\begin{array}{c}\text { Longitu- } \\
\text { dinal }\end{array}$ & $\begin{array}{c}3.04- \\
3.95\end{array}$ & $\begin{array}{c}810- \\
1524\end{array}$ \\
\hline $\begin{array}{c}\text { Behiri and } \\
\text { Bonfield } \\
\text { (1989) }\end{array}$ & $\begin{array}{c}\text { Bovine } \\
\text { tibia }\end{array}$ & $\begin{array}{c}\text { Longitu- } \\
\text { dinal }\end{array}$ & 3.2 & - \\
\hline $\begin{array}{c}\text { Norman et } \\
\text { al. (1992) }\end{array}$ & $\begin{array}{c}\text { Bovine } \\
\text { tibia }\end{array}$ & $\begin{array}{c}\text { Longitu- } \\
\text { dinal }\end{array}$ & 6.67 & 1191 \\
\hline
\end{tabular}

II.

Table 2 Summary of previous research.

\begin{tabular}{|c|c|c|}
\hline Ref. & Description & Conclusion/ Recommendation \\
\hline$[4]$ & $\begin{array}{l}\text { Mouse femora were notched on the posterior surface at their } \\
\text { mid-diaphysis and tested in three-point bending using an in } \\
\text { situ loading stage within an ESEM }\end{array}$ & $\begin{array}{l}\text { 3D morphological characterization of the microcrack } \\
\text { damage does not provide measurements of the bone } \\
\text { toughness and its evolution in relation to the crack path } \\
\text { and extension. }\end{array}$ \\
\hline$[5]$ & $\begin{array}{c}\text { Experimental study and numerical simulations of fracture } \\
\text { processes in a bovine femoral cortical bone tissue using } \\
\text { single-edge-notch-bending specimen in a three-point } \\
\text { bending setup. }\end{array}$ & $\begin{array}{l}\text { Bone demonstrated a non-uniform elastic-plastic } \\
\text { fracture process for different cortices. } \\
\text { Fracture toughening mechanisms varied for different } \\
\text { fracture propagation directions. }\end{array}$ \\
\hline$[7]$ & $\begin{array}{c}\text { Finite element study on fracture energy of bone under pure } \\
\text { mode II loading. } \\
\text { Trapezoidal law is used on simulate fracture behaviour. }\end{array}$ & $\begin{array}{l}\text { Proposed miniaturized end notched flexure test is } \\
\text { appropriate for bone fracture characterization under } \\
\text { mode II loading. }\end{array}$ \\
\hline [9] & $\begin{array}{c}\text { Plain strain assumptions of linear elastic fracture mechanics } \\
\text { (LEFM) to bone were investigated. Fracture toughness tests } \\
\text { were used to assess the crack inhibiting effect of human } \\
\text { bone microstructure on fracture resistance. }\end{array}$ & $\begin{array}{c}\text { The toughness of human and bovine bone is still } \\
\text { questionable. }\end{array}$ \\
\hline$[10]$ & $\begin{array}{l}\text { Assess the accuracy of beam theory, which were tested on } \\
\text { mice. Structure of femora was measured by micro- } \\
\text { computed tomography. Tissue modulus was calculated from } \\
\text { beam theory using micro-FE results }\end{array}$ & $\begin{array}{l}\text { Re-evaluation of the tissue properties obtained from } \\
\text { three-point bending especially in mouse genetics }\end{array}$ \\
\hline$[11]$ & $\begin{array}{c}\text { Development of FE model based on continuum damage } \\
\text { mechanics (CDM) approach to simulate the damage } \\
\text { initiation and propagation of a single trabecula till complete } \\
\text { fracture. }\end{array}$ & $\begin{array}{l}\text { Consideration of time-dependent mechanical } \\
\text { behaviour of bone (loading rate). } \\
\text { Further investigation is required to develop anisotropic } \\
\text { damage models for bone at tissue level. }\end{array}$ \\
\hline$[12]$ & $\begin{array}{l}\text { Experimental study of the mechanical behaviour and } \\
\text { fracture toughness of bovine bone under tensile and bending } \\
\text { test. }\end{array}$ & $\begin{array}{l}\text { Water content affects the ability of deforming and } \\
\text { dissipating energy under mechanical loading, leading } \\
\text { to a more ductile material. }\end{array}$ \\
\hline$[13]$ & $\begin{array}{l}\text { A reference point indentation technique (BioDent) was } \\
\text { developed to determine bone's resistance to fracture. }\end{array}$ & $\begin{array}{l}\text { Further study of the indentation distance increase (IDI) } \\
\text { values and other BioDent indentation parameters in ex } \\
\text { vivo models. }\end{array}$ \\
\hline$[14]$ & $\begin{array}{c}\text { Investigation of the osteonal-, micro- and tissue-level } \\
\text { mechanical behaviour of human cortical bone tissue } \\
\text { samples from young ang elderly donors using atomic force } \\
\text { microscope (AFM) }\end{array}$ & $\begin{array}{l}\text { Further research to establish the homogenisation of } \\
\text { nanoelastic features that is a function of ageing and } \\
\text { whether it is a change occurring in osteoporotic bone. }\end{array}$ \\
\hline
\end{tabular}




\section{Conclusion}

Limitation associated with current clinical fracture risk assessment tools highlight the need for increased understanding of the fracture mechanisms of the bone. Additional knowledge on the quality of the bone is essential for predicting and reducing the fracture risk associated with age and diseases. This review indicates study on bone fracture mostly been conducted in human bone, mouse bone and bovine bone. By interpreting mouse and bovine bone in terms of human bone toughness can enhance the progress of pre-clinical testing for translational medicine aimed to reduce bone fracture risks. Most researchers used three-point bending test as it was easy to conduct and create initial crack for fracture toughness calculation. Hence, more research should be done by using finite element tools as it is the safe and non-invasive technique.

\section{References}

1. R. Barlett, Sports Biomechanics: Reducing Injury and Improving Performance, Routledge, London (1999).

2. K.J. Koester, J.W. Ager, R.O. Ritchie. The True Toughness of Human Cortical Bone Measured with Realistically Short Cracks. Nat. Mater. 7 (2008), 672 $-677$.

3. H. Peterlik, P. Roschger, K. Klaushofer and P. Fratzl. From Brittle to Ductile Fracture of Bone. Nat. Mater. 5, pp. $52-55$, (2006).

4. A. Carriero, E. A. Zimmermann, S. J. Shefelbine and R. O. Ritchie. A Methodology for The Investigation of Toughness and Crack Propagation in Mouse Bone. Journal of the Mechanical Behavior of Biomedical Materials 39, pp. 38 - 47, (2014).

5. S. Li, A.A Wahab, V.V Silberschmidt. Analysis of Fracture Process In Cortical Bone Tissue. Engineering Fracture Mechanics 110, pp. 448-458, (2013).

6. British Standards Institue. Fracture Mechanics Toughness Tests. Method for Determination of $\mathrm{K}_{\mathrm{IC}}$,
Critical CTOD and Critical J Values of Metallic Materials. BS 7448-1, (1999).

7. N. Dourado, F.A.M. Pereira, M.F.S.F. Moura, J.J.L. Morais and M.I.R Dias. Bone Fracture Characterization Using the End Notched Flexure Test. Materials Science and Engineering C33, pp. 405-410, (2013).

8. F.G.A. Silva, M.F.S.F de Moura, N. Dourado, J. Xavier, F.A.M. Pereira, J.J.L Morais and M.I.R. Dias. Mixed-Mode I+II Fracture Characterization of Human Cortical Bone Using The Single Leg Bending Test. Journal of The Mechanical Behavior of Biomedical Materials 54, pp. 72-81, (2016).

9. T. L. Norman, D. Vashishth and D. B. Burr. Fracture Toughness of Human Bone Under Tension. J. Biomechanics, 28, pp. 309-32(1995)0.

10. G. H. V. Lenthe, R. Voide, S. K. Boyd and R. Muller. Tissue Modulus Calculated From Beam Theory is Biased by Bone Size and Geometry: Implications for The Use of Three-Point Bending Tests to Determine Bone Tissue Modulus. Bone, 43, pp. 717-723, (2008).

11. H. Ridha and P. J. Thurner. Finite Element Prediction with Experimental Validation of Damage Distribution in Single Trabaculea During ThreePoint Bending Tests. Journal of The Mechanical Behavior of Biomedical Materials 27, pp. 94-106, (2013).

12. F. Libonati and L. Vergani. Bone Toughness and Crack Propagation: An Experimental Study. Procedia Engineering 74, pp. 464-467, (2014).

13. A. Carriero, J.L. Bruse, K.J. Oldknow, J.L. Millan, C. Farquharson and S.J. Shefelbine. Reference Point Indentation Is Not Indicative of Whole Mouse Bone Measures of Stress Intensity Fracture Toughness. Bone 69, pp. 174-179, (2014).

14. O.L. Katsamenis, T. Jenkins and P.J. Thurner. Toughness and Damage Susceptibility In Human Cortical Bone Is Proportional to Mechanial Inhomogeneity At The Osteonal-Level. Bone, 76, pp. 158-168, (2015). 